\title{
Intramammary infusion of Escherichia coli lipopolysaccharide negatively affects feed intake, chewing, and clinical variables, but some effects are stronger in cows experiencing subacute rumen acidosis
}

\author{
S. Aditya, ${ }^{*} †$ E. Humer, ${ }^{*}$ P. Pourazad, ${ }^{*}$ R. Khiaosa-Ard, ${ }^{*}$ J. Huber, $\ddagger$ and Q. Zebeli* \\ *Institute of Animal Nutrition and Functional Plant Compounds, Department for Farm Animals and Veterinary Public Health, \\ University of Veterinary Medicine Vienna, Veterinaerplatz 1,1210 Vienna, Austria \\ †Directorate General of Human Resource for Science, Technology, and Higher Education-Indonesia, 10270 Jakarta, Indonesia \\ łUniversity Clinic for Ruminants, Clinical Unit for Herd Health Management in Ruminants, Department for Farm Animals \\ and Veterinary Public Health, University of Veterinary Medicine Vienna, Veterinaerplatz 1, 1210 Vienna, Austria
}

\begin{abstract}
Feeding high-grain diets increases the risk of subacute rumen acidosis (SARA) and adversely affects rumen health. This condition might impair the responsiveness of cows when they are exposed to external infectious stimuli such as lipopolysaccharide (LPS). The main objective of this study was to evaluate various responses to intramammary LPS infusion in healthy dairy cows and those experimentally subjected to SARA. Eighteen early-lactating Simmental cows were subjected to SARA $(\mathrm{n}=12)$ or control $(\mathrm{CON} ; \mathrm{n}=6)$ feeding conditions. Cows of the control group received a diet containing $40 \%$ concentrates (DM basis) throughout the experiment. The intermittent SARA feeding regimen consisted in feeding the cows a ration with $60 \%$ concentrate (DM basis) for $32 \mathrm{~d}$, consisting of a first SARA induction for $8 \mathrm{~d}$, switched to the CON diet for $7 \mathrm{~d}$, and re-induction during the last $17 \mathrm{~d}$. On $\mathrm{d}$ 30 of the experiment, 6 SARA (SARA-LPS) and 6 CON (CON-LPS) cows were intramammary challenged once with a single dose of $50 \mu \mathrm{g}$ of LPS from Escherichia coli (O26:B6), whereas the other 6 SARA cows (SARA-PLA) received $10 \mathrm{~mL}$ of sterile saline solution as placebo. To confirm the induction of SARA, the reticular $\mathrm{pH}$ was continuously monitored via wireless $\mathrm{pH}$ probes. The DMI remained unchanged between SARA and CON cows during the feeding experiment, but was reduced in both treatment groups receiving the LPS infusion compared with SARA-PLA, whereby a significant decline was observed for cows of the SARA-LPS treatment $(-38 \%)$ compared with CON-LPS $(-19 \%)$. The LPS infusion did not affect the reticuloruminal $\mathrm{pH}$ dynamics, but significantly enhanced ruminal temperature and negatively affected chewing behavior. The ruminal temperature increased after the LPS infusion and peaked about $1 \mathrm{~h}$ earlier in SARA-LPS cows
\end{abstract}

Received July 29, 2016.

Accepted October 7, 2016.

${ }^{1}$ Corresponding author: Qendrim.Zebeli@vetmeduni.ac.at compared with the cows of the CON-LPS treatment. Moreover, a significant decline in milk yield was found in SARA-LPS compared with CON-LPS following the LPS infusion. Cows receiving LPS had elevated somatic cell counts, protein, and fat contents in milk as well as decreased lactose contents and $\mathrm{pH}$ following the LPS infusion, whereby the changes in milk constituents were more pronounced in SARA-LPS than CON-LPS cows. Rectal temperature and pulse rate were highest $6 \mathrm{~h}$ after LPS infusion, but rumen contractions were not affected by the LPS infusion. The data suggest that a single intramammary LPS infusion induced fever and negatively affected feed intake, chewing activity, rectal temperature, and milk yield and composition, whereby these effects were more pronounced in SARA cows.

Key words: dairy cow, Escherichia coli lipopolysaccharide, subacute ruminal acidosis, fever

\section{INTRODUCTION}

Dairy cows are typically fed energy-dense diets rich in highly digestible nonstructural carbohydrates to fulfill their high energy requirements. This type of feeding impairs chewing behavior and most importantly leads to accumulation of large amounts of VFA in the rumen fluid (Kleen and Cannizzo, 2012). Ruminants need long chewing periods, whereby impaired chewing activity hampers rumen buffering, which, together with the accumulation of large amounts of VFA, lowers ruminal $\mathrm{pH}$, thus increasing the risk of SARA (Kleen et al., 2003; Hernández et al., 2014). Subacute ruminal acidosis is a prevalent health concern, particularly in cows during early lactation, and causes major economic losses to the dairy industry (Garrett et al., 1997; Plaizier et al., 2008). The severity and duration of SARA conditions are particularly relevant for rumen health (Khafipour et al., 2009; Schwaiger et al., 2013). Recent research of our team observed that intermittent SARA conditions are stronger than persistent SARA conditions, likely because the rumen and its microbiota have 
less chance to adapt and the VFA are less absorbed across the reticulorumen wall (Pourazad et al., 2016; Qumar et al., 2016; Wetzels et al., 2016). The latter is a major concern, as VFA absorption is essential for the regulation of the intraruminal $\mathrm{pH}$ and the alleviation of SARA conditions (Aschenbach et al., 2011; Schwaiger et al., 2013).

The rumen plays an important role not only in supplying energy and nutrients, but also in modulating the overall health of the cow (Zebeli and Metzler-Zebeli, 2012). The SARA has been associated with the initiation of a chain of metabolic and microbial alterations and dysbiosis in the rumen (Khafipour et al., 2009; Steele et al., 2011), which are implicated in multiple metabolic health disorders in dairy cows. For example, research has shown that cows experiencing SARA are more susceptible to laminitis (Nocek, 1997), metabolic disturbances and inflammation (Plaizier et al., 2008; Zebeli et al., 2011), milk fat depression syndrome (Zebeli and Ametaj, 2009; Dong et al., 2014), liver abscesses and displaced abomasum, and that these cows suffer often from off-feed and ketosis (Kleen et al., 2003; Plaizier et al., 2008; Zebeli et al., 2015). Thus, cows experiencing SARA might be more susceptible to external infectious stimuli such as those occurring during acute mastitis challenge compared with cows that did not experience SARA conditions. However, the responses in feed intake, chewing behavior, rumen, milk, and clinical variables in cows experiencing SARA conditions to an acute mastitis challenges have not been yet investigated. An accurate model of naturally occurring acute gram-negative mastitis in dairy cows is the experimentally induced single intramammary LPS challenge (Brooker et al., 1981; Shuster et al., 1993).

We hypothesized that cows subjected to an intermittent and long-term SARA feeding regimen (Pourazad et al., 2016) and exposed to a single intramammary LPS challenge have lower feed intake, impaired chewing behavior and milk yield, and a stronger response in clinical variables compared with a control group that was not subjected to SARA conditions. This study aimed to investigate the effects of a single intramammary LPS infusion on DMI, chewing activity, rumen $\mathrm{pH}$, and temperature as well as milk variables, and other health parameters such as rectal temperature, pulse rate, and rumen contractions in dairy cows experiencing intermittently induced SARA conditions or not.

\section{MATERIALS AND METHODS}

\section{Animal, Experimental Design, and Diets}

The experimental procedures were approved by the Institutional Ethics Committee of the University of Veterinary Medicine Vienna (Vetmeduni Vienna) and the
National Authority of Austria according to $\$ 26$ of the Law for Animal Experiments, Tierversuchsgesetz 2012TVG (GZ BMWFW-68.205/0096-WF/V/3b/2015).

The experiment was conducted at the Dairy Research Station of the University of Veterinary Medicine Vienna (Pottenstein, Austria). A total of 18 early lactating Simmental cows $(712.3 \pm 101.3 \mathrm{~kg}$ of BW; $66.6 \pm 20.4$ DIM; 8 primiparous and 10 multiparous) without a history of mastitis and with a SCC of less than 200,000 cells $/ \mathrm{mL}$ in all quarters were enrolled in this study. The cows were blocked by DIM and lactation number and assigned to 2 different feeding groups: control $(\mathbf{C O N} ; \mathrm{n}=6)$ and SARA $(\mathrm{n}=12)$. Cows of the CON group received the same diet throughout the experiment, consisting of a TMR that contained $27 \%$ concentrates (DM basis), whereby these cows had additional access to a concentrate mixture for dairy cows at a maximum allowance of $4 \mathrm{~kg}$ per cow and day (Table 1), reaching an overall concentrate level of approximately $40 \%$ of the total daily DMI. The SARA feeding regimen was an intermittent concentrate-rich feeding challenge, as adapted from Pourazad et al. (2016). This feeding challenge consisted of feeding cows a TMR with $60 \%$ concentrate (Table 1) for $8 \mathrm{~d}$ (SARA 1), switched for $7 \mathrm{~d}$ (SARA break) to the same feeding management as the CON cows, and subsequently stepped up to the $60 \%$ concentrate-TMR for the last $17 \mathrm{~d}$ of the experiment, whereby the first and the second week of this time were denoted as SARA 2 and SARA 3, respectively, and the remaining $3 \mathrm{~d}$ were the intramammary LPS challenge.

Fresh TMR were mixed daily using a feeding and mixing robot (Triomatic T15, Trioliet Feeding Technology, Oldenzaal, the Netherlands) and offered twice a day $(0800$ and $1500 \mathrm{~h})$ to the cows in individual electronically regulated feeding troughs (Insentec B.V., Marknesse, the Netherlands). The TMR were available ad libitum, and feed refusals, reaching between 5 and $10 \%$ of the offered feed, were removed before offering the fresh feed in the morning. Also, the daily concentrate allowances for cows of the CON group and of the SARA group during the 7-d SARA break were supplied twice, at 1000 and $1600 \mathrm{~h}$, in separate automatic feeding troughs (Insentec B.V.), based on the profile of reticuloruminal $\mathrm{pH}$. This separate and controlled access to concentrate ensured that the respective cows did not experience SARA while meeting their requirements of energy and nutrients. The concentrate refusals were also removed before offering the fresh concentrate in the morning of the next day. The amount of feeds consumed daily was recorded electronically by the feeding troughs.

Diets were formulated according to GfE (2001) guidelines to meet or exceed the energy and nutrient 
requirements of $700 \mathrm{~kg}$ cows producing $35 \mathrm{~kg}$ of milk/d with $4.0 \%$ fat and $3.4 \%$ protein. The cows had free access to water throughout the trial.

\section{Reticuloruminal $\mathrm{pH}$ and Temperature and Monitoring of SARA Conditions}

Reticuloruminal $\mathrm{pH}$ and temperature were measured continuously throughout the experiment using wireless bolus sensors (Smaxtec Animal Care Sales GmbH, Graz, Austria). By using an applicator, these validated bolus sensors (Klevenhusen et al., 2014) were manually administered via the esophagus into the reticulorumen. Prior to their use, the boli were calibrated using a buffer solution at $\mathrm{pH} 7.0$ following the company instructions and were registered to the computer software device afterward. A wireless antenna was installed in the free

Table 1. Ingredients and nutrient composition of the control and SARA diets

\begin{tabular}{lcc}
\hline Item & Control & SARA \\
\hline Ingredient (\% of DM) & 58.0 & 31.0 \\
Grass silage & 15.0 & 9.0 \\
Hay & 23.0 & 14.0 \\
Grain mix $^{1}$ & 4.0 & 0 \\
Protein supplement $^{2}$ & 0 & 46.0 \\
Concentrate mixture $^{3}$ & & \\
Chemical composition (\% of DM) & 42.4 & 51.7 \\
DM & 91.4 & 91.9 \\
OM & 16.6 & 17.0 \\
CP & 2.0 & 1.8 \\
Ether extract & 26.8 & 20.5 \\
ADF & 40.9 & 33.5 \\
NDF & 31.8 & 39.6 \\
NFC & 6.66 & 7.44 \\
NE $_{\mathrm{L}}(\mathrm{MJ} / \mathrm{kg}$ of DM) & & \\
\hline
\end{tabular}

${ }^{1}$ Contained $50 \%$ corn, $47 \%$ wheat, and $3 \%$ mineral and vitamin premix and consisted of (DM basis): $96.7 \% \mathrm{OM}, 11.9 \% \mathrm{CP}, 3.2 \%$ ether extract, $14.4 \% \mathrm{NDF}, 67.2 \% \mathrm{NFC}, 8.17 \mathrm{MJ}$ of $\mathrm{NE}_{\mathrm{L}}, 2.5 \mathrm{~g}$ of calcium, 5.45 $\mathrm{g}$ of phosphorus, $7.05 \mathrm{~g}$ of sodium, $3.18 \mathrm{~g}$ of magnesium, 33,975 IU of vitamin A, 5,097 IU of vitamin $\mathrm{D}$, and $136 \mathrm{mg}$ of vitamin $\mathrm{E}$.

${ }^{2}$ Contained $60 \%$ rapeseed meal, $21.5 \%$ dried distillers grains with solubles, $8 \%$ soybean meal, $3 \%$ rye bran, $2.9 \%$ sugar beet molasses, $2.6 \%$ urea, and $2 \%$ mineral and vitamin premix and consisted of (DM basis): 92.0\% OM, $45.5 \%$ CP, $3.4 \%$ ether extract, $28.9 \%$ NDF, $13.9 \%$ NFC, $7.61 \mathrm{MJ}$ of $\mathrm{NE}_{\mathrm{L}}, 10.23 \mathrm{~g}$ of calcium, $10.23 \mathrm{~g}$ of phosphorus, $3.41 \mathrm{~g}$ of sodium, $5.68 \mathrm{~g}$ of magnesium, $18 \mathrm{mg}$ of copper, $80 \mathrm{mg}$ of zinc, $45 \mathrm{mg}$ of manganese, $1 \mathrm{mg}$ of selenium, $0.6 \mathrm{mg}$ of cobalt, $4 \mathrm{mg}$ of iodine, 18,182 IU of vitamin A, $1,818 \mathrm{IU}$ of vitamin $\mathrm{D}_{3}$, and $34 \mathrm{mg}$ of vitamin $\mathrm{E}$.

${ }^{3}$ Contained $63 \%$ barley, $18 \%$ soybean meal, $9.4 \%$ rapeseed meal, $5.9 \%$ beet pulp, $2.0 \%$ mineral premix (contained $1.13 \%$ calcium, $0.91 \%$ phosphorus, $0.26 \%$ sodium, $0.50 \%$ magnesium, 13,683 IU of vitamin A, 1,824 IU of vitamin D, $46 \mathrm{mg}$ of vitamin E, $91 \mathrm{mg}$ of iron, $114 \mathrm{mg}$ of manganese, $68 \mathrm{mg}$ of zinc, and $17 \mathrm{mg}$ of copper), $1.15 \%$ calcium carbonate, $0.1 \%$ salt, $0.5 \%$ monocalcium phosphate, and consisted of (DM basis): $93.1 \%$ OM, $20.8 \%$ CP, $2.28 \%$ ether extract, $8.92 \%$ ADF, $19 \% \mathrm{NDF}, 51 \% \mathrm{NFC}, 8.62 \mathrm{MJ}$ of $\mathrm{NE}_{\mathrm{L}}$. The concentrate mixture was also offered to the control cows separately at maximum of $4 \mathrm{~kg}$ per cow and day to reach a level of approximately $40 \%$ concentrate of the total DMI.

${ }^{4} \mathrm{NFC}=[100-(\mathrm{CP}+\mathrm{NDF}+$ ash + ether extract $)]$. stall to communicate with the sensors. Both temperature and $\mathrm{pH}$ data were received every $10 \mathrm{~min}$ from the wireless antenna. Mean $\mathrm{pH}$ values as well as the total time of $\mathrm{pH}$ below a threshold of 6.0 were calculated throughout the entire experiment. Besides the diurnal temperature dynamics, also the mean, minimum, and maximum temperature as well as the total time and area of temperature above a threshold of $39.5^{\circ} \mathrm{C}$ were calculated. As the boli are located in the reticulum within $24 \mathrm{~h}$ after administration and reticular $\mathrm{pH}$ readings are on average 0.24 units higher than ruminal $\mathrm{pH}$ readings (Falk et al., 2016), the criterion for the occurrence of SARA conditions in this study was a reticuloruminal $\mathrm{pH}$ below 6.0 for at least 5 to $6 \mathrm{~h} / \mathrm{d}$ as recently adapted to Zebeli et al. (2008) in a validation study conducted by V. Neubauer, E. Humer, I. Kroeger, T. Braid, M. Wagner, and Q. Zebeli (Institute of Animal Nutrition and Functional Compounds, Vetmeduni Vienna, Austria).

\section{Intramammary LPS Infusion}

The intramammary LPS infusion occurred on $\mathrm{d}$ 30 of the experiment, $3 \mathrm{~h}$ after the morning milking. Cows were restrained shortly before the infusion, and the teats were cleaned with cotton wool dipped in $70 \%$ ethanol (Prima, Spillern, Austria). Thereafter, half of the SARA cows (SARA-LPS) and all CON cows (CON-LPS) received a direct injection of $50 \mu \mathrm{g}$ LPS from Escherichia coli (O26:B6; Sigma-Aldrich Inc., St. Louis, MO), diluted in $10 \mathrm{~mL}$ of sterile $\mathrm{NaCl}$ solution (B. Braun, Melsungen, Germany) into the left front quarter using a sterile plastic syringe (BOVIVET Patteansats, Langeskov, Denmark) and wearing sterile gloves. The remaining 6 SARA cows (SARA-PLA) received $10 \mathrm{~mL}$ of a sterile $\mathrm{NaCl}$ solution as a placebo.

\section{Chewing Activity}

The chewing activity was recorded using wireless chewing halters (RumiWatch System, Forschungsanstalt Agroscope Reckenholz-Tänikon, Ettenhausen, Switzerland; ITIN + HOCH GmbH, Fütterungstechnik, Liestal, Switzerland) the day before, as well as during LPS challenge and the following $12 \mathrm{~h}$. The RumiWatch halter, consisting of a noseband sensor with a liquidfilled tube, a pressure tube, a pressure sensor, and a connection cable, recorded the jaw movements of the cows. The raw data were calculated every $1 / 10 \mathrm{~s}$ and saved on a micro SD card attached to the RumiWatch halter. By using the USB reader antenna, the raw data were transferred to the software RumiWatch manager using a wireless system. Furthermore, the data were processed using the software RumiWatch. All measured 
data were used to compute the time spent eating and ruminating, as well as the total chewing time, the number of boli, the chews per bolus, as well as the chews per minute following the procedures described by Zehner et al. (2012).

\section{Clinical Health Parameters}

To monitor the clinical status of the cows, rectal temperature, pulse rate, and rumen contractions were measured shortly before, as well as 2, 4, 6, 8, 12, 24, 36 , and $48 \mathrm{~h}$ after the infusion of LPS. Rectal temperature was measured using a rectal thermometer (Henry Schein Medical, Vienna, Austria) and pulse rate and rumen contractions were measured using a stethoscope.

\section{Feed Sampling and Chemical Analyses}

Feed and feed refusal samples were collected once a week for proximate analysis. All analyses were conducted in duplicate according to the German Handbook of Agricultural Experimental and Analytical Methods (VDLUFA, 2012). Prior to analyses, the samples were dried at $65^{\circ} \mathrm{C}$ for $48 \mathrm{~h}$ and ground to pass a $0.5-\mathrm{mm}$ screen afterward (Retsch, Haan, Germany). The DM was determined by drying in an oven at $100^{\circ} \mathrm{C}$ for 24 $\mathrm{h}$. Ash was analyzed using muffle furnace at a temperature of $580^{\circ} \mathrm{C}$ overnight. The $\mathrm{CP}$ content was determined using the Kjeldahl method and ether extract was assayed using Soxhlet extraction. The NDF and ADF were analyzed following Van Soest et al. (1991), with heat stable $\alpha$-amylase in the NDF procedure and both fiber fractions were expressed exclusive of residual ash. The NFC were computed as NFC $=100-(\mathrm{CP}+\mathrm{NDF}$ + ash + ether extract). The content of $\mathrm{NE}_{\mathrm{L}}$ in feeds was estimated according to GfE (2001).

\section{Milk Data}

The cows were milked twice daily, at 0730 and 1730 $\mathrm{h}$, in a tandem milking parlor. Milk yields were noted automatically using an electronic machine recorder (DeLaval Corp., Tumba, Sweden). From d 30 to 32 foremilk samples were manually taken from the left front quarter during the morning and afternoon milking and analyzed separately for SCC, protein, fat, lactose, urea, and $\mathrm{pH}$ by Combifoss (Foss, Hillerød, Denmark). Also, before enrolling in the experiment as well as before and after the LPS challenge, the SCC was analyzed. Additionally, udder health was monitored using the California Mastitis Test (SCC <200,000; DeLaval Corp.) at the start of the experiment and following LPS infusion to detect clinical mastitis.

\section{Statistical Analyses}

The data were evaluated by ANOVA using the MIXED procedure of SAS (version 9.2, SAS Institute Inc., Cary, NC). For each variable tested, the model included the fixed effects of time (i.e., day, hour, minute, or time interval) and group (CON, SARA) or treatment (CON-LPS, SARA-LPS, SARA-PLA), respectively, as well as the interaction time $\times$ group/treatment. The measurements carried out on the day before LPS infusions were considered as covariate in the statistical analysis to obtain the effects of the LPS infusion per se. The individual cows were considered as random effects. The data obtained on the same cow but at different times were considered as repeated measurements with a first order autoregressive variance-covariance matrix. The pdiff option was used for each LSM comparison. Furthermore, for assessing the overall effect of the LPS infusion, an orthogonal contrast involving the average of the 2 LPS treatments versus PLA was tested. Differences among LSM with $P<0.05$ were considered as representing significant differences, and differences among LSM with $0.05 \leq P<0.10$ were accepted as representing tendencies.

\section{RESULTS}

\section{Feed Intake and Reticuloruminal $\mathrm{pH}$ Before LPS Infusion}

Data of total DMI and differences in reticuloruminal $\mathrm{pH}$ between CON and SARA cows, measured before the LPS challenge, are shown in Table 2. Data were summarized between both SARA groups (SARA-LPS and SARA-PLA) as no differences in all variables were observed between the SARA cows that underwent LPS or PLA infusion later. Data showed that the DMI of cows did not differ between the different feeding groups (SARA vs. CON; $P=0.63$ ), but increased in the SARA group after the first SARA challenge $(P<0.05)$.

The different feeding regimens affected the reticuloruminal $\mathrm{pH}$ readings in CON versus SARA cows during the high-grain feeding times (SARA 1-3) but not during the SARA break, where they were fed the same diet (Table 2). Lower mean $\mathrm{pH}$ values were observed in SARA cows compared with CON cows during all SARA challenge times $(P<0.01)$. More specifically, during the SARA 1, which represents the first week of feeding $60 \%$ concentrate, mean reticuloruminal $\mathrm{pH}$ and time duration of $\mathrm{pH}<6.0$ were 6.07 and $571 \mathrm{~min} / \mathrm{d}$, respectively, in the SARA group. During the SARA 2 and 3, which corresponded to wk 1 and 2 after the 1-wk SARA break, the mean pH values of SARA cows were 6.14 and 6.17 , respectively, thus being higher com- 
pared with the first SARA challenge $(P<0.01)$. In agreement, compared with SARA 1, cows of the SARA group spent less time below $\mathrm{pH} 6.0$ in SARA 2 and 3 (on average 404 and $355 \mathrm{~min} / \mathrm{d}$, respectively, $P<0.05$ ). Nevertheless, the mean reticuloruminal $\mathrm{pH}$ was lower, as well as the time duration of $\mathrm{pH}<6.0$ was extended compared with CON cows during all SARA challenge times. More specifically, the CON cows had an average $\mathrm{pH}$ of 6.28 and spent $137 \mathrm{~min} / \mathrm{d}$ below $\mathrm{pH} 6.0$ throughout the entire feeding time before LPS infusion.

\section{Feed Intake and Chewing Activity Relative to LPS Infusion}

As shown in Figure 1a, DMI related to metabolic BW $\left(\mathrm{BW}^{0.75}\right)$ across the first $12 \mathrm{~h}$ after the LPS infusion was reduced in cows receiving the LPS compared with PLA $(-19 \%$ in cows of treatment CON-LPS and $-38 \%$ in cows of treatment SARA-LPS compared with SARAPLA; $P<0.01)$. As revealed by an interaction between treatment and time $(P=0.04)$, the DMI suppression was more pronounced in the SARA-LPS treatment as compared with the CON-LPS treatment during the first $8 \mathrm{~h}(P<0.01$, Figure 1a).

Figure 1b shows the time spent eating after the LPS/ PLA infusion. A trend toward an interaction between treatment and time $(P=0.07)$ demonstrates a shorter time spent eating in SARA-LPS compared with CONLPS during the first $4 \mathrm{~h}$ after the LPS infusion $(P=$ 0.04), whereas the differences diminished thereafter. However, both treatment groups receiving LPS lowered the eating time similarly from 4 to $12 \mathrm{~h}$ after the LPS infusion compared with SARA-PLA $(P<0.05)$. The time spent ruminating was also reduced by about $35 \%$ in cows receiving LPS compared with PLA $(P=0.01)$, and the decline was especially pronounced 4 to $8 \mathrm{~h}$ after LPS infusion $(P<0.01$, Figure 1c). In agreement, the total chewing time was negatively affected by the LPS infusion $(P<0.01$, Figure 1d). An interaction between time and treatment $(P<0.01)$ revealed that SARA-LPS cows responded with a significant decline in the chewing activity almost the first $4 \mathrm{~h}$ after the LPS infusion $(P=0.07)$, whereas the chewing activity of the CON-LPS cows was only affected thereafter $(P<$ 0.05). In total, cows of the SARA-LPS treatment spent the shortest time with chewing $(97 \mathrm{~min})$ during the first $12 \mathrm{~h}$ after the LPS infusion, which was especially pronounced compared with SARA-PLA (153 min, $P<$ 0.01 ), but also tendentially lower compared with CONLPS (118 min, $P=0.06$ ). In accordance to the time spent ruminating, fewer boli were rejected from the LPS-challenged cows $(P=0.02$, Figure 2a), and they differed especially during the interval 4 to $8 \mathrm{~h}$ after infusion $(P<0.01)$. Also, a difference was noticed for the chews per bolus among treatments $(P<0.01$, Figure $2 \mathrm{~b}$ ), showing lowest numbers in SARA-LPS with on average 28 chews compared with 42 in CON-LPS and 50 in SARA-PLA $(P<0.05)$. The chews per minute are presented in Figure 2c, demonstrating a significant decline in cows of the SARA-LPS treatment (on average 31) compared with CON-LPS (53) and SARA-PLA $(52 ; P \leq 0.01)$.

Table 2. The DMI and reticuloruminal $\mathrm{pH}$ in dairy cows experiencing $(\mathrm{n}=12)$ or $\operatorname{not}(\mathrm{n}=6)$ SARA conditions ${ }^{1}$

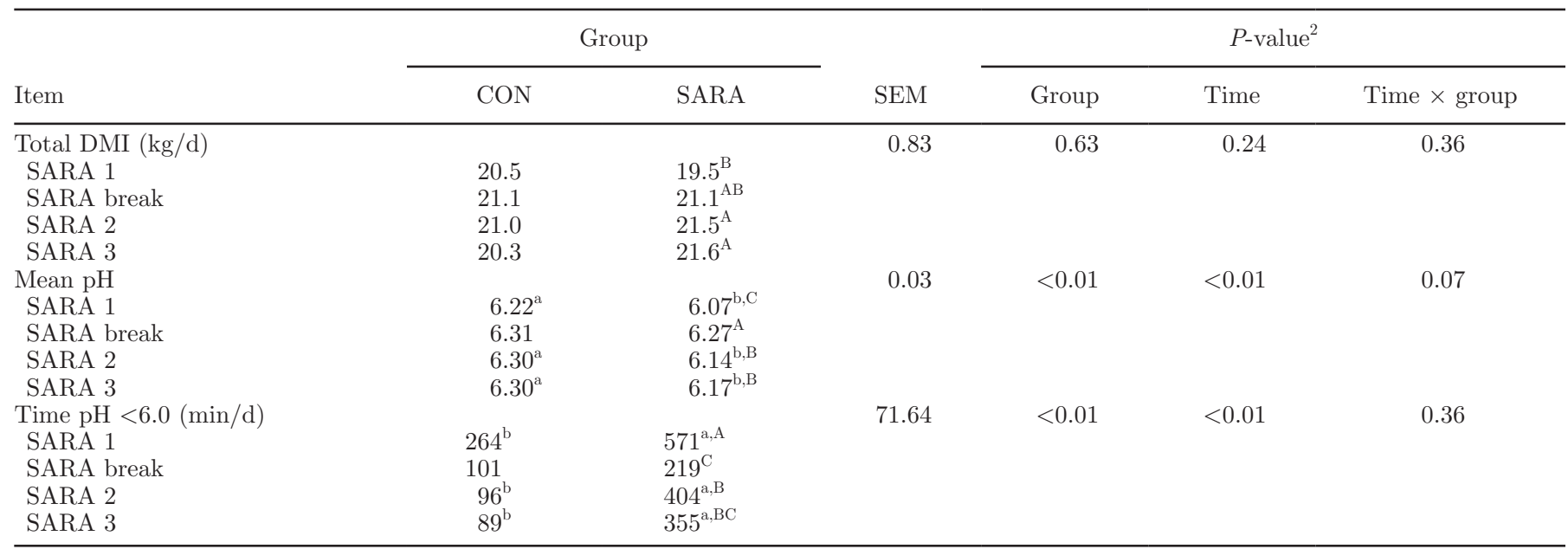

${ }_{\mathrm{a}, \mathrm{b}}$ Different superscripts indicate differences among LSM of the same row at $P<0.05$.

${ }^{\mathrm{A}-\mathrm{C}}$ Different superscripts indicate differences among LSM of the same column at $P<0.05$.

${ }^{1}$ The SARA feeding protocol consisted of feeding cows $60 \%$ concentrates for $8 \mathrm{~d}$ (SARA 1), followed by $7 \mathrm{~d}$ with the control (CON) diet (SARA break) and finally of $14 \mathrm{~d}$ of $60 \%$ concentrates (the first $7 \mathrm{~d}$ were considered as SARA 2, whereas the last $7 \mathrm{~d}$ were denoted as SARA 3 ). The CON feeding was approximately $40 \%$ concentrates throughout the trial.

${ }^{2}$ Effect of feeding treatment (group), time, interactive effect of group and time (group $\times$ time). 


\section{Reticuloruminal $\mathrm{pH}$ and Temperature Relative to LPS Infusion}

The effect of experimentally LPS-induced mastitis on reticuloruminal $\mathrm{pH}$ during the first $12 \mathrm{~h}$ after the LPS administration is demonstrated in Figure $3 \mathrm{a}$. The LPS infusion did not affect the reticuloruminal $\mathrm{pH}$ dynamics $(P=0.23)$. In addition, the mean $\mathrm{pH}$ as well as the time spent below 6.0 did not differ among the treatments (Table 3 ). In contrast, the intramammary LPS injection affected the reticuloruminal temperature dynamics, showing a significant increase from $4 \mathrm{~h}$ after the infusion onward $(P<0.01$; Figure $3 \mathrm{~b})$. Whereas the maximum ruminal temperature in SARA-LPS was reached $6.6 \mathrm{~h}$ after infusion and also declined earlier, the response of the cows of CON-LPS in terms of the temperature change was postponed by about $1 \mathrm{~h}$. The analyses of the reticuloruminal temperature per time interval after LPS infusion are summarized in Table 3. Whereas no difference in the mean temperature was found among treatments during the first $4 \mathrm{~h}$, a significant increase in both LPS treatment groups was shown thereafter $(P<0.01)$. Following the average temperature data, the maximum temperature was also higher in cows treated with LPS than PLA $(P<$ $0.01)$. Nevertheless, an interaction between treatment and time $(P<0.01)$ demonstrated that the maximum temperature reached higher values from 8 to $12 \mathrm{~h}$ after LPS infusion in CON-LPS cows compared with their SARA-LPS counterparts $(P=0.01)$. Additionally, the
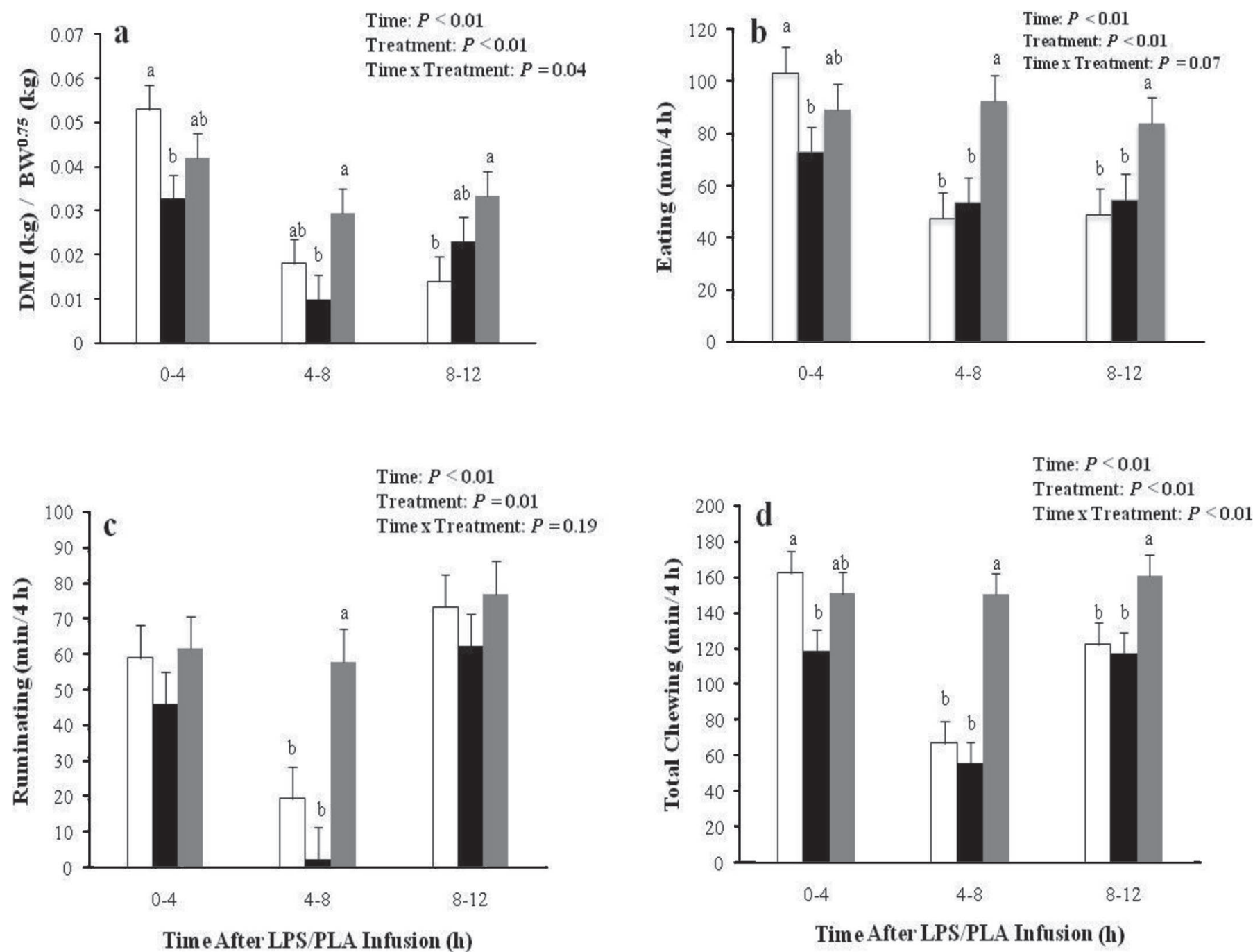

Time After LPS/PLA Infusion (h)

Figure 1. Dry matter intake related to metabolic $\mathrm{BW}\left(\mathrm{BW}^{0.75}\right.$; a), time spent eating (b), time spent ruminating (c), and total chewing time (d) in lactating cows fed a control diet and receiving a LPS infusion (CON-LPS; open bars) or a SARA diet and receiving either a LPS (SARALPS; black bars) or placebo infusion (SARA-PLA; gray bars) during 3 different time intervals (0-4, 4-8, and 8-12 h after LPS/PLA infusion). Data are shown as LSM \pm SEM. Statistically significant differences between groups and within a timepoint are indicated by different letters $(P<0.05)$. 

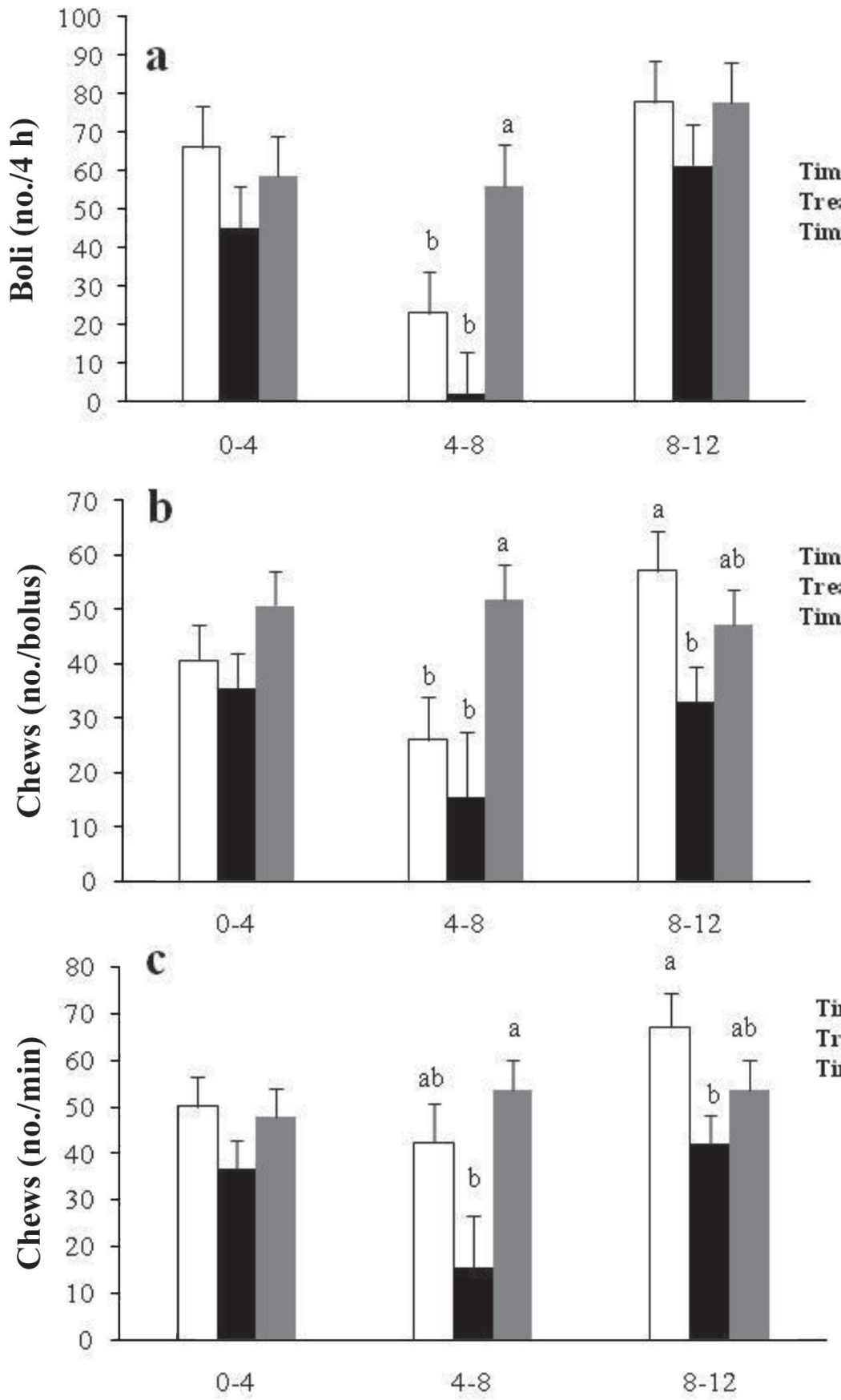

Time: $P<0.01$

Treatment: $P=0.04$

Time x Treatment: $P=0.22$

Time: $P=0.13$

Treatment: $\boldsymbol{P}<\mathbf{0 . 0 1}$

Time $\mathrm{x}$ Treatment: $P=0.16$

Time: $P=0.01$

Treatment: $P=0.01$

Time $\mathrm{x}$ Treatment: $P=0.20$

Time After LPS/PLA Infusion (h)

Figure 2. Number of boli (a), chews per bolus (b), and chews per minute (c) in lactating cows fed a control diet and receiving a LPS infusion (CON-LPS; open bars) or a SARA diet and receiving either a LPS (SARA-LPS; black bars) or placebo infusion (SARA-PLA; gray bars) during 3 different time intervals $(0-4,4-8$, and 8-12 h after LPS/PLA infusion). Data are shown as LSM \pm SEM. Statistically significant differences between groups and within a timepoint are indicated by different letters $(P<0.05)$.

time and area (temperature $\times$ time) of the temperature $>39.5^{\circ} \mathrm{C}$ increased from 4 to $12 \mathrm{~h}$ after the LPS infusion in both LPS treatment groups $(P=0.01)$, but remained without differences between CON-LPS and SARA-LPS.

\section{Pulse Rate, Rectal Temperature, and Rumen Contractions Relative to LPS Infusion}

A significant increase in the rectal temperature after the LPS infusion was observed in cows receiv- 

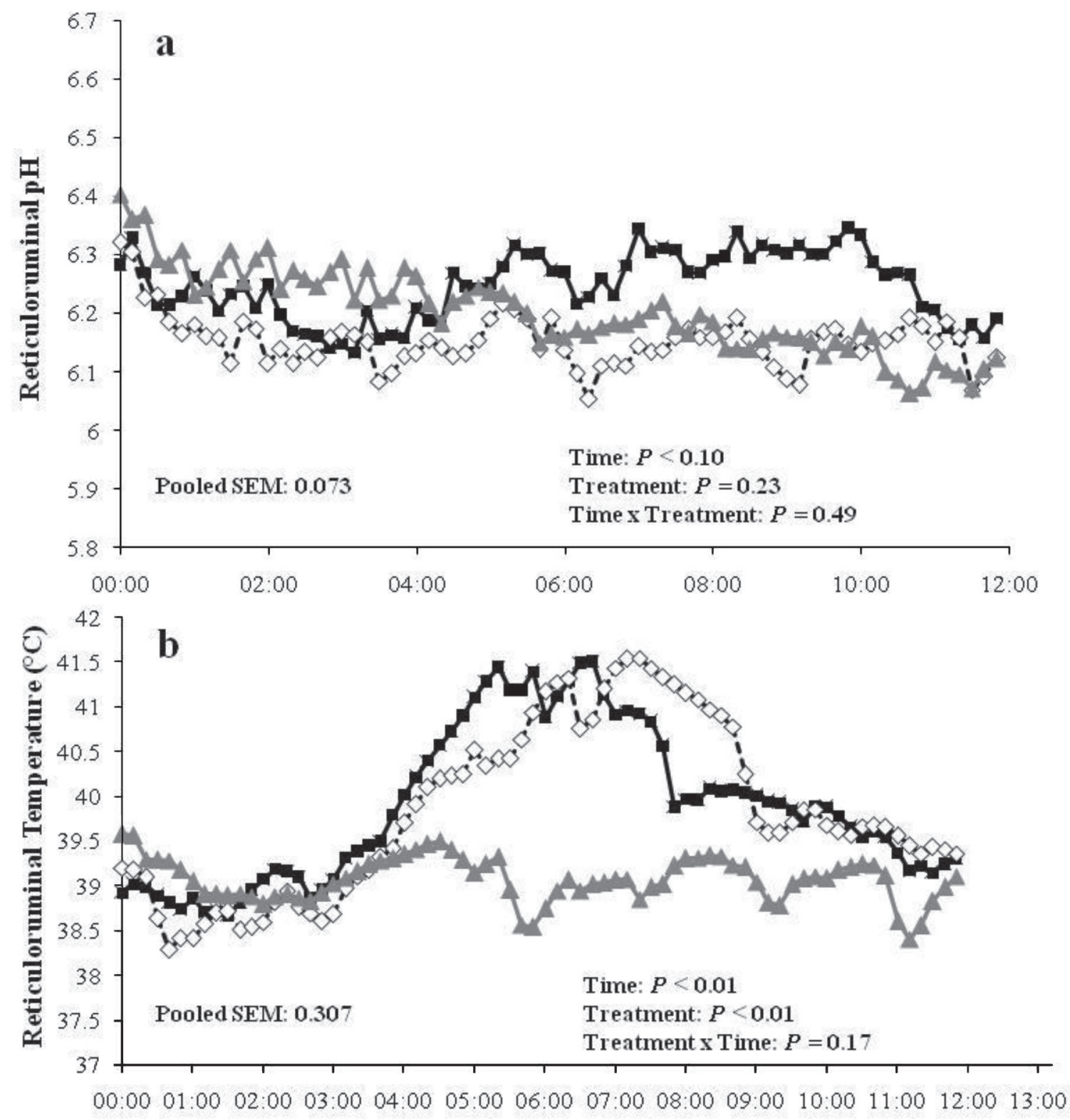

Time after LPS infusion (h)

Figure 3. Reticuloruminal pH (a) and temperature dynamics (b) in lactating cows fed a control diet and receiving a LPS infusion (CONLPS; diamonds) or a SARA diet and receiving either a LPS (SARA-LPS; squares) or placebo infusion (SARA-PLA; triangles), during the first $12 \mathrm{~h}$ after LPS/PLA infusion.

ing LPS $(P<0.01)$, whereas the temperature of the SARA-PLA cows remained stable between 38.2 and $38.6^{\circ} \mathrm{C}$ throughout all measurement times after the PLA infusion. In cows receiving the LPS treatment, rectal temperature increased from $4 \mathrm{~h}$ after the LPS challenge onward, peaked at $40.5^{\circ} \mathrm{C} 6 \mathrm{~h}$ after the infusion, and reached the PLA treatment comparable temperature again $12 \mathrm{~h}$ after the challenge (Figure $4 \mathrm{a}, P=0.01)$. Effects of LPS infusion on pulse rate are shown in Figure 4b. The pulse rate significantly increased at 6 and $8 \mathrm{~h}$ after the LPS infusion (on average 95 beats per min) in both LPS treatment groups compared with SARA-PLA (on average 85 beats per min, $P<0.05$ ). No significant difference was observed for rumen contractions among the treatments (SARA-PLA; $1.03 \pm 0.03 \mathrm{n} / \mathrm{min}$, CON-LPS; $1.07 \pm 0.03 \mathrm{n} / \mathrm{min}$, SARA-LPS; $1.05 \pm 0.03 \mathrm{n} / \mathrm{min}$; $P=0.69)$. 
Table 3. Reticuloruminal $\mathrm{pH}$ and temperature in cows fed a control diet and receiving a LPS infusion (CON-LPS) or a SARA diet and receiving either a LPS (SARA-LPS) or placebo infusion (SARA-PLA) during 3 different time intervals (0-4, 4-8, and 8-12 h after LPS/PLA infusion)

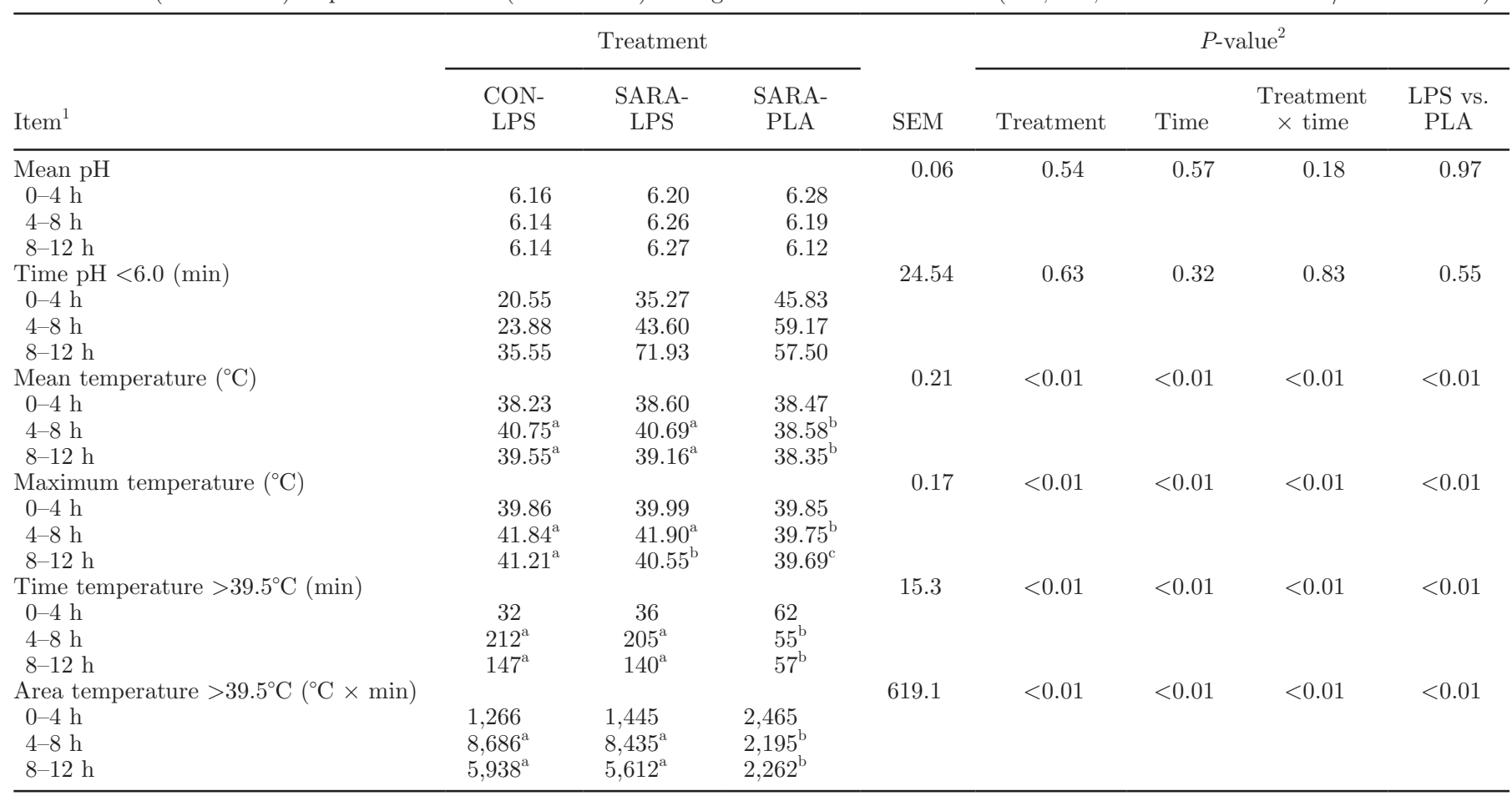

${ }^{\mathrm{a}-\mathrm{c}}$ Different superscripts indicate differences among LSM in the same row at $P<0.10$.

${ }^{1} \mathrm{pH}$ and temperature were measured every 10 min.

${ }^{2}$ Effect of treatment (treatment), time after LPS infusion (time), interactive effect of treatment and time (treatment $\times$ time), and overall effect of LPS infusion (LPS vs. PLA).

\section{Milk Yield and Composition Relative to LPS Infusion}

As shown in Figure 5a, an overall decline in milk yield after LPS infusion was found in both LPS treatment groups compared with their PLA counterparts $(P$ $<0.01$ ). Interestingly, a decline in milk yield was also found in SARA-LPS compared with CON-LPS following the LPS infusion $(P=0.05)$, and the differences reached significance 24 and $36 \mathrm{~h}$ after the LPS infusion. Cows receiving LPS had elevated SCC following the LPS infusion until the end of the observation time $(P<$ 0.01 , Figure 5b); however, no difference was noticed between CON-LPS and SARA-LPS $(P=0.71)$. Furthermore, significant differences in protein concentrations in the foremilk were found after LPS infusion, with LPS-challenged cows having higher protein contents compared with PLA cows $(P=0.05)$. Whereas the LPS infusion significantly increased the protein content in the SARA cows from 24 until $48 \mathrm{~h}$ after the challenge, a significant difference in CON-LPS vs. SARA-LPS cows was only found $36 \mathrm{~h}$ after the LPS injection (interaction between treatment and time: $P=0.02$, Figure $5 \mathrm{c}$ ). In addition, the LPS challenge caused an elevated milk fat content $(P=0.05$; Figure $5 \mathrm{~d})$. An interaction between treatment and time $(P<0.01)$, revealed an increase in the fat content starting $24 \mathrm{~h}$ after the LPS infusion in CON-LPS as well as SARA-LPS cows. Whereas no difference was found $36 \mathrm{~h}$ after the LPS challenge in CON-LPS cows compared with SARA-PLA cows, SARA-LPS cows remained at an elevated level until 36 $\mathrm{h}$ after the infusion. Furthermore, the lactose content declined almost $12 \mathrm{~h}$ after the LPS challenge in both LPS-challenged treatment groups $(P<0.01$; Figure 5 e); however, whereas the SARA-LPS cows showed a lower concentration until the end of the observation time, the differences between CON-LPS and SARAPLA became insignificant from $48 \mathrm{~h}$ after the infusion onward. The milk urea nitrogen concentrations did not differ among treatments (data not shown), but milk $\mathrm{pH}$ declined in cows challenged with LPS compared with their PLA-counterparts $(P<0.01)$; however, no difference was observed between CON-LPS and SARA-LPS cows (Figure 5f).

\section{DISCUSSION}

The present study was performed to evaluate the effect of a single intramammary LPS infusion on feed 
intake, chewing activity, reticuloruminal $\mathrm{pH}$, milk parameters as well as further health-related variables in dairy cows subjected to an intermittent and long-term SARA-feeding regimen before LPS infusion. The SARA regimen consisted in intermittent feeding of $60 \%$ concentrate for $8 \mathrm{~d}$, followed by a SARA break for $7 \mathrm{~d}$ with the same feeding management as the CON cows, and subsequently stepped up to the $60 \%$ concentrate for the remaining $17 \mathrm{~d}$, which resulted in depressed reticuloruminal $\mathrm{pH}$ during the feeding challenges, reaching the SARA threshold [Zebeli et al., 2008; V. Neubauer, E. Humer, I. Kroeger, T. Braid, M. Wagner, and Q. Zebeli (Institute of Animal Nutrition and Functional Compounds, Vetmeduni Vienna, Austria)]. In contrast, the CON cows were fed a moderate but common concentrate level (approximately 40\%) in dairy cow feeding, which, as intended, maintained the cows above the threshold of SARA conditions, while meeting their requirements in energy and nutrients. The SARA typically has been associated with a chain of metabolic and
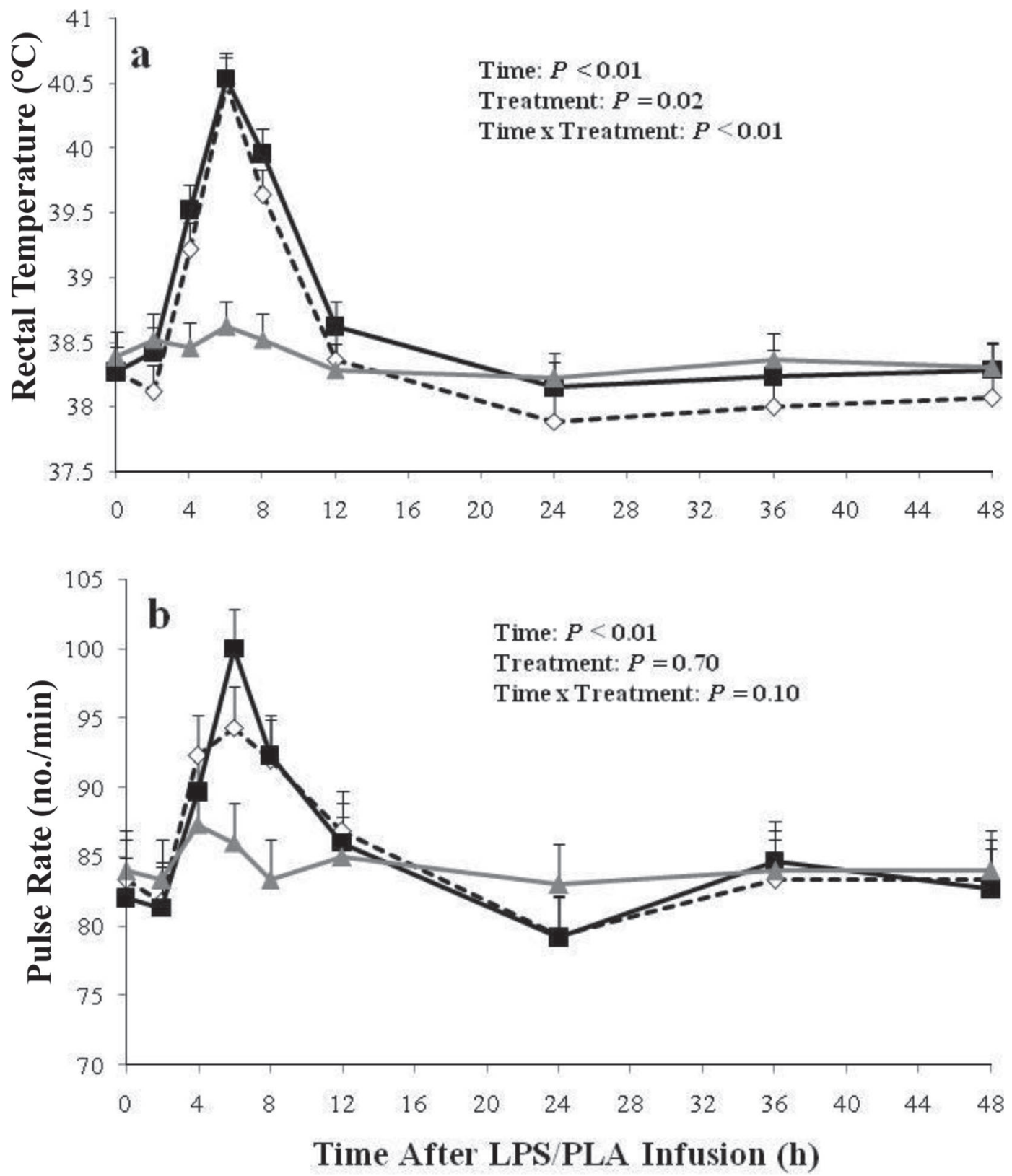

Figure 4. Rectal temperature (a) and pulse rate (b) in lactating cows fed a control diet and receiving a LPS infusion (CON-LPS; diamonds) or a SARA diet and receiving either a LPS (SARA-LPS; squares) or placebo infusion (SARA-PLA; triangles), measured shortly before as well as $2,4,6,8,12,24,36$, and $48 \mathrm{~h}$ after the LPS/PLA infusion. Data are shown as LSM $\pm \mathrm{SEM}$. 

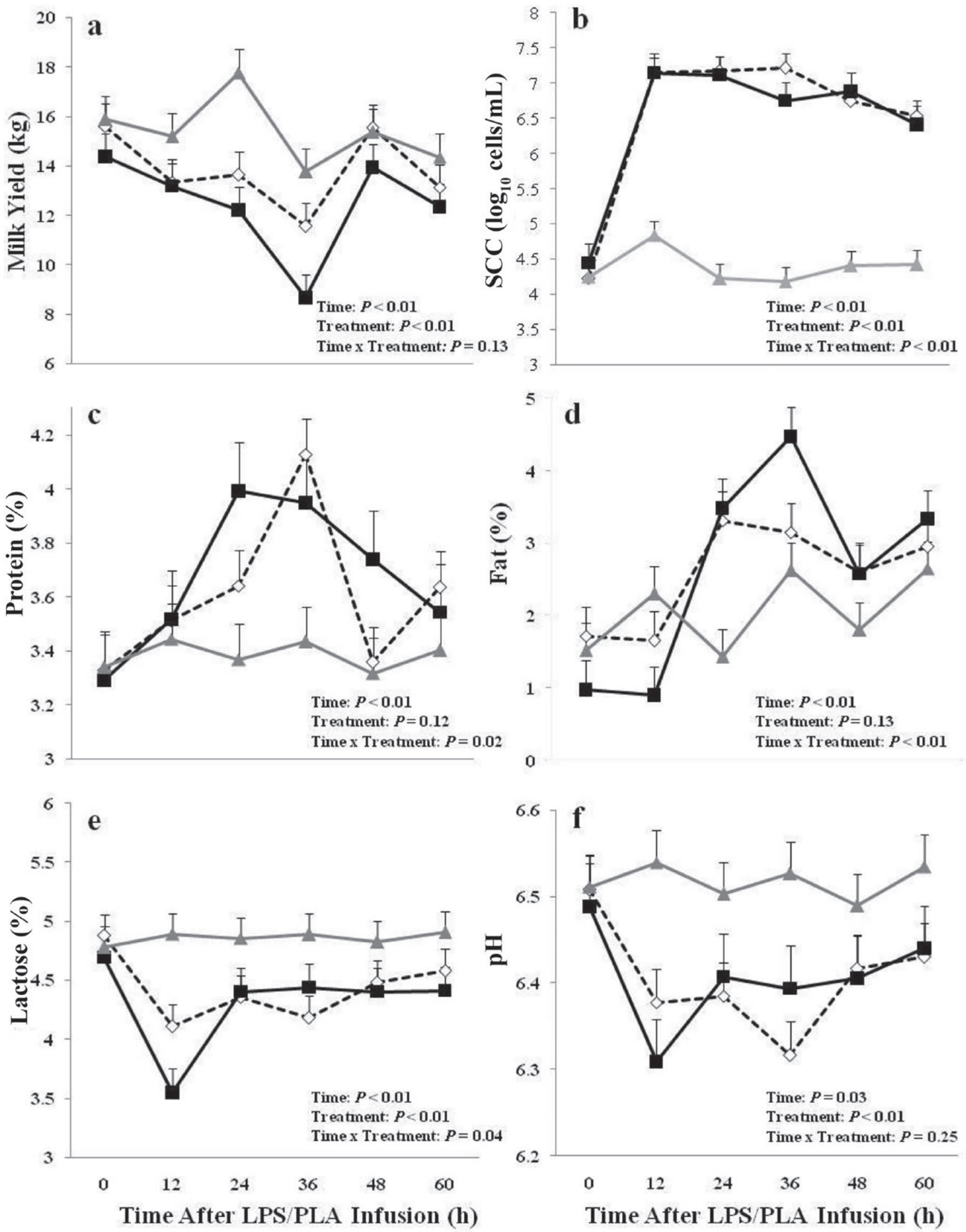

Figure 5. Milk yield (a), SCC (b), protein (c), fat (d), lactose (e), and milk pH (f) in lactating cows fed a control diet and receiving a LPS infusion (CON-LPS; diamonds) or a SARA diet and receiving either a LPS (SARA-LPS; squares) or placebo infusion (SARA-PLA; triangles) before as well as $12,24,36,48$, and $60 \mathrm{~h}$ after the LPS/PLA infusion. Data are shown as LSM \pm SEM. 
microbial alterations in the rumen, adversely affecting rumen and systemic health of the cows (Plaizier et al., 2008). Our main hypothesis was that cows experiencing repeated periods of SARA (Pourazad et al., 2016) are more responsive to external infectious stimuli due to such alterations in the digestive tract. Indeed, our results demonstrated that a single intramammary LPS challenge led to a faster increase in ruminal temperature as well as a stronger decline in feed intake, chewing activity, and milk yield in cows subjected to an intermittent SARA feeding regimen compared with cows receiving a lower concentrate level continuously.

More specifically, the cows that received an intramammary LPS infusion showed a reduced DMI and chewing activity compared with cows that received an intramammary PLA infusion, whereby cows of the SARA-feeding regimen showed a faster and stronger decline in DMI, total chewing time as well as number of chews per minute and bolus. As eating and ruminating activities in dairy cows are considered as quintessential behaviors, their observation provides helpful information in terms of health conditions (González et al., 2008; Braun et al., 2013). The present results can be explained by the pro-inflammatory response to LPS that induces classical signs of sickness behavior that is comparable to cows suffering from acute, clinical mastitis (Sepúlveda-Varas et al., 2016). Furthermore, our results are in agreement with previous studies, reporting that intramammary LPS challenge induced obvious clinical symptoms such as decreased DMI only a few hours after infusion of E. coli (Fogsgaard et al., 2012; Lüttgenau et al., 2016). However, the stronger responsiveness in cows experiencing SARA compared with the control cows is a new finding that deserves further investigations. In a recent study, Gott et al. (2015) subjected cows to different starch feeding regimen (control vs. high starch vs. acidosis diets) and intramammary infused $10 \mu \mathrm{g}$ of LPS (E. coli O111:B4) after $20 \mathrm{~d}$ of feeding the different diets. Although an overall decline in DMI was observed, no difference in the response of the cows of the different feeding regimen was found. Also, AlZahal et al. (2011) investigated cows receiving diets with a moderate forage:concentrate (52:48 in DM) and high forage:concentrate (65:35 in DM) for $21 \mathrm{~d}$, which were challenged intramammary with $100 \mu \mathrm{g}$ of LPS (E. coli O111:B4). Decreasing DMI occurred after LPS infusion but without differing effects among the feeding groups. Possible explanations for the different results in our study compared with previous studies might be due the fact the SARA feeding challenge was long and cows experienced 2 intermittent SARA bouts, which are stronger than a single SARA bout (Pourazad et al., 2016). Also, different doses and serotypes of LPS used might also have contributed to these discrepant results.

In accordance to the DMI, the reduced chewing time due to LPS infusion indicates effects of clinical disease emergence and is in agreement with Zimov et al. (2011), who showed that cows spent less time eating and chewing after an intramammary challenge with $25 \mu \mathrm{g}$ of LPS (E. coli O6:B26). Fitzpatrick et al. (2013) also observed reduced ruminating time in cows after infusion of 25 $\mu \mathrm{g}$ of LPS derived from E. coli O111:B4. Despite the general effect of LPS infusion versus PLA, the time spent chewing and the number of boli decreased more strongly in SARA cows receiving LPS compared with CON cows, showing a strong deviation from normal values (Jeroch et al., 2008). This finding suggests more pronounced clinical symptoms during experimental E. coli mastitis in cows experiencing SARA, which might necessitate greater attention and care to restore their feed intake and chewing behavior compared with healthy cows.

Reticuloruminal $\mathrm{pH}$ was not affected by intramammary LPS infusion. Similar results have been observed by AlZahal et al. (2011), who found no effect of an intramammary infusion of $100 \mu \mathrm{g}$ of LPS (E. coli O111:B4) on ruminal $\mathrm{pH}$ in cows receiving either a high forage:concentrate TMR or a TMR with a moderate forage:concentrate ratio. The reason might be the decreased DMI observed in cows receiving LPS, which concomitantly decreases fermentation processes. Therefore, a lower production of VFA would be expected to increase ruminal $\mathrm{pH}$; however, one has to consider that ruminal $\mathrm{pH}$ is the product of fermentation as well as salivary and mucosal neutralization processes (Aschenbach et al., 2011). Therefore, the reduced chewing activities in LPS-challenged cows are likely responsible for the missing effect on ruminal $\mathrm{pH}$ despite lower DMI.

More importantly, higher ruminal temperature as well as time durations of the temperature above $39.5^{\circ} \mathrm{C}$ were detected in response to the LPS infusion, whereby SARA-LPS cows responded with a faster temperature rise than their CON counterparts. Although the fever inducing effect of intramammary LPS infusion has been reported in previous studies to be accompanied by rising ruminal temperature (AlZahal et al., 2011), the faster response in SARA cows is a new finding that further strengthens our initial hypothesis. In agreement, also a previous study by AlZahal et al. (2011) demonstrated different responses in certain ruminal temperature variables to an intramammary LPS infusion in cows subjected to different concentrate levels. More specifically, the time duration of ruminal temperature above $38.8^{\circ} \mathrm{C}$ following LPS challenge was higher in cows subjected to a moderate forage:concentrate diet than in cows 
receiving a high forage:concentrate diet. However, the exact mechanisms behind some overreaction responses to the LPS challenge in cows subjected to SARA compared with healthy cows are unclear so far and deserve further investigations.

Similar to ruminal temperature, rectal temperature showed a significant increase after LPS infusion with a peak $6 \mathrm{~h}$ thereafter as reported before (Vels et al., 2009; Lüttgenau et al., 2016). An overall high correlation between rectal and ruminal temperature was found in our study, indicating that ruminal temperature measurements are effective in capturing febrile responses of the LPS treatment, as reported previously (AlZahal et al., 2011). Unlike ruminal temperature, rectal temperature responses did not differ between SARA-LPS and their CON counterparts. This might be explained by the continuous measurements obtained with the wireless devices, which are more likely to capture changes in the temperature compared with intermittent measurements as conducted rectally. Furthermore, along with increased rectal temperature, pulse rate jumped to abnormal levels 6 and $8 \mathrm{~h}$ after LPS infusion (on average 95 beats per min) in cows treated with LPS treatment, but reached normal pulse rates (about 86 beats per minute, Divers and Peek, 2008) $12 \mathrm{~h}$ thereafter. The peak value of pulse rate coincided with the peak value of rectal temperature $\left(40.5^{\circ} \mathrm{C}\right)$ indicating certain stress induced by cortisol changes. In agreement with previous studies, heart rate increased following LPS infusion (Vels et al., 2009; Hagiwara et al., 2014; Lüttgenau et al., 2016). However, in the present study no alteration of the rumen contractions was found due to LPS infusion. This indicates that intramammary infusion of LPS ( $E$. coli $\mathrm{O} 26: \mathrm{B} 6)$ at a dosage of $50 \mu \mathrm{g}$ did not induce reticuloruminal stasis, a hazardous sign associated with LPS as an effect of endotoxicosis (Eades, 1993, 1997; Andersen, 2003). Perkins et al. (2002) observed a decrease in rumen contractions after intramammary LPS $(E$. coli O111:B4) infusion at a dosage of $100 \mu \mathrm{g}$. However, in agreement with our study Gott et al. (2015) observed no changes in rumen motility in cows receiving $10 \mu \mathrm{g}$ of E. coli (O111:B4), suggesting dose-dependent responses of this variable.

As shown as a clinical inflammatory sign, the LPS challenge induced a strong increase in SCC (Wellnitz et al., 2011; Vernay et al., 2012; Gott et al., 2015). Our findings revealed no difference in SCC between SARA-LPS and CON-LPS cows. Interestingly, Gott et al. (2015) found a significantly higher SCC in cows fed control and acidosis (designed to cause acute bouts of ruminal $\mathrm{pH}$ depression) diets compared with cows fed high starch (formulated to induce chronic ruminal $\mathrm{pH}$ depression) diets after intramammary LPS infusion, thus suggesting a certain endotoxin tolerance at the local level of the mammary gland. Nevertheless, the underlying mechanisms have not been clarified so far.

Furthermore, the observed changes in the milk constituents corroborate the characteristic alterations that have been reported during clinical mastitis (Shuster et al., 1991; Auldist et al., 1995; Auldist and Hubble, 1998). For instance, increased milk protein concentrations have been observed, likely resulting from the disruption of the mammary epithelia cells that in turn increases influx of blood-borne proteins such as serum albumin and immunoglobulins (Auldist et al., 1995; Auldist and Hubble, 1998). Interestingly, cows subjected to the SARA-LPS treatment responded with a faster and also longer increase in the protein content than their CON-LPS counterparts. Also, milk fat concentrations increased after the LPS infusion, whereas the opposite was noticed for lactose. These findings are supported by previous studies (Shuster et al., 1991; Pyorala, 2003; Bruckmaier et al., 2004). In accordance to the milk protein concentration, the differences between the cows that were infused LPS compared with the cows that were infused PLA were longer pronounced in SARA-LPS cows compared with CON-LPS. A possible reason might be that SARA-cows were already subjected to LPS, which might have been translocated from the gastrointestinal tract to the mammary gland (Dong et al., 2014).

Furthermore, a stronger decline in the milk yield in SARA-LPS cows compared with CON-LPS cows after the LPS challenge was found in the present study. In contrast, AlZahal et al. (2011) and Gott et al. (2015) found no difference regarding the decline in milk yield following LPS challenge in dairy cows subjected to different feeding regimen. Although possible reasons for the different results regarding the milk yield between studies are unclear, differences regarding the LPS serotype and dosage as well as diets used might be important factors whether hyperresponsiveness to an external infectious stimuli would occur or not.

Hitherto little research has been conducted on the responsiveness of ruminants to a single LPS challenge after prolonged exposure to low amounts of LPS. The few studies that have been performed to date indicate that the response might differ among animal factors (Elsasser et al., 1996; Bieniek et al., 1998; Gott et al., 2015). Moreover, it has been reported from human studies that precedent LPS exposure leads to different responses upon subsequent toxic doses of LPS, depending on the doses and exposure duration (Morris and $\mathrm{Li}$, 2012). More specifically, low doses can induce a state of endotoxin tolerance to a subsequent exposure to a high dose of LPS, but very low doses can even have an opposite effect (Ametaj et al., 2012; Petzl et al., 2012). Lastly, the present findings should be evaluated 
with further research using different dosages of LPS to distinguish whether cows would experience tolerance or even an overreaction.

\section{CONCLUSIONS}

Our results revealed that an experimentally induced LPS insult in the udder induced fever as well as negatively affected DMI, chewing activity, milk yield and milk composition, whereby cows subjected to SARA were more responsive to the intramammary LPS challenge than the non-SARA cows. The data also suggest more pronounced clinical symptoms after LPS infusion in cows experiencing SARA, which might necessitate greater attention and care to restore their feed intake, chewing behavior, milk, and clinical variables compared with cows that do not experience SARA. Further research is warranted to elucidate the mechanistic relationships behind the changes in variables due to SARA conditions and the experimentally induced mastitis challenge.

\section{ACKNOWLEDGMENTS}

The authors acknowledge W. Pohl, A. Käfer, E. Draxler, G. Erwin, D. Fleischhacker, K. Günther, K. Dienbauer, P. Kanz, and H. Pothmann (Dairy research station Kremesberg at Vetmeduni Vienna) for their help and excellent technical assistance with the animal trial. We thank A. Fengel, K. Wiesböck, and M. Qumar (students at Vetmeduni Vienna) for their help during the experiment. We thank A. Dockner, S. Eisen, S. Sharma, and M. Wild (Institute of Animal Nutrition and Functional Plant Compounds, Vetmeduni Vienna) for their assistance with laboratory analyses and experimental material preparation. We thank the Qualitätslabor Niederösterreich (Gmünd, Austria) for milk analyses. The first author thanks the Austrian Agency for International Cooperation (Österreichischer Austauschdienst, OEAD) in Education and Research, the ASEAN-European Academic University Network (ASEA UNINET) for the PhD program financial support in Austria. We gratefully acknowledge the Vienna Science and Technology Fund (Wiener Wissenschafts-, Forschungs- und Technologiefonds, WWTF) for the support of this research (project D-I.INFLACOW, LS12-010).

\section{REFERENCES}

AlZahal, O., H. AlZahal, M. A. Steele, M. Van Schaik, I. Kyriazakis, T. F. Duffield, and B. W. McBride. 2011. The use of a radiotelemetric ruminal bolus to detect body temperature changes in lactating dairy cattle. J. Dairy Sci. 94:3568-3574.
Ametaj, B. N., S. Sivaraman, S. M. Dunn, and Q. Zebeli. 2012. Repeated oral administration of lipopolysaccharide from Escherichia coli O111:B4 modulated humoral immune responses in periparturient dairy cows. Innate Immun. 18:638-647.

Andersen, P. H. 2003. Bovine endotoxicosis-Some aspects of relevance to production diseases. A review. Acta Vet. Scand. Suppl. 98:141155.

Aschenbach, J. R., G. B. Penner, F. Stumpff, and G. Gäbel. 2011. Ruminant nutrition symposium: Role of fermentation acid absorption in the regulation of ruminal pH. J. Anim. Sci. 89:1092-1107.

Auldist, M. J., S. Coats, G. L. Rogers, and G. H. McDowell. 1995 Changes in the composition of milk from healthy and mastitic dairy cows during the lactation cycle. Aust. J. Exp. Agric. 35:427436.

Auldist, M. J., and I. B. Hubble. 1998. Effects of mastitis on raw milk and dairy products. Aust. J. Dairy Technol. 53:28-36.

Bieniek, K., A. Szuster-Ciesielska, T. Kamińska, M. Kondracki, M. Witek, and M. Kandefer-Szerszeń. 1998. Tumor necrosis factor and interferon activity in the circulation of calves after repeated injection of low doses of lipopolysaccharide. Vet. Immunol. Immunopathol. 62:297-307.

Braun, U., L. Trösch, F. Nydegger, and M. Hässig. 2013. Evaluation of eating and rumination behaviour in cows using a noseband pressure sensor. BMC Vet. Res. 9:164.

Brooker, B. E., A. J. Frost, and A. W. Hill. 1981. At least two toxins are involved in Escherichia coli mastitis. Experientia 37:290.

Bruckmaier, R. M., C. E. Ontsouka, and J. W. Blum. 2004. Fractionized milk composition in dairy cows with subclinical mastitis. Vet. Med-Czech. 8:283-290.

Divers, T. J., and S. F. Peek, ed. 2008. Rebhun's Diseases of Dairy Cattle. 2nd ed. Saunders Elsevier, St. Louis, MO.

Dong, G., M. Qiu, C. Ao, J. Zhou, Khas-Erdene, X. Wang, Z. Zhang, and Y. Yang. 2014. Feeding a high-concentrate corn straw diet induced epigenetic alterations in the mammary tissue of dairy cows. PLoS One 9:e107659.

Eades, S. C. 1993. Endotoxemia in dairy cattle: Role of eicosanoids in reticulorumen stasis. J. Dairy Sci. 76:414-420.

Eades, S. C. 1997. Endotoxaemia in dairy cattle: Mechanism of reticulorumen stasis. Vet. J. 153:321-327.

Elsasser, T. H., M. Richards, R. Collier, and G. F. Hartnell. 1996 Physiological responses to repeated endotoxin challenge are selectively affected by recombinant bovine somatotropin administration to calves. Domest. Anim. Endocrinol. 13:91-103.

Falk, M., A. Münger, and F. Dohme-Meier. 2016. Technical note: A comparison of reticular and ruminal $\mathrm{pH}$ monitored continuously with 2 measurement systems at different weeks of early lactation. J. Dairy Sci. 99:1951-1955.

Fitzpatrick, C. E., N. Chapinal, C. S. Petersson-Wolfe, T. J. DeVries, D. F. Kelton, T. F. Duffield, and K. E. Leslie. 2013. The effect of meloxicam on pain sensitivity, rumination time, and clinical signs in dairy cows with endotoxin-induced clinical mastitis. J. Dairy Sci. 96:2847-2856.

Fogsgaard, K. K., C. M. Røntved, P. Sørensen, and M. S. Herskin. 2012. Sickness behavior in dairy cows during Escherichia coli mastitis. J. Dairy Sci. 95:630-638.

Garrett, E. F., K. V. Nordlund, W. J. Goodger, and G. R. Oetzel. 1997. A cross-sectional field study investigating the effect of periparturient dietary management on ruminal $\mathrm{pH}$ in early lactation dairy cows. J. Dairy Sci. 80:169. (Abstr.)

Gesellschaft für Ernährungsphysiologie (GfE). 2001. Empfehlungen zur Energie- und Nährstoffversorgung der Milchkühe und Aufzuchtrinder. Nr. 8, DLG Verlag, Frankfurt am Main, Germany.

González, L. A., B. J. Tolkamp, M. P. Coffey, A. Ferret, and I. Kyriazakis. 2008. Changes in feeding behavior as possible indicators for the automatic monitoring of health disorders in dairy cows. J. Dairy Sci. 91:1017-1028.

Gott, P. N., J. S. Hogan, and W. P. Weiss. 2015. Effects of various starch feeding regimens on responses of dairy of cows to intramammary lipopolysacccharide infusion. J. Dairy Sci. 98:1786-1796.

Hagiwara, S., K. Mori, H. Okada, S. Oikawa, and H. Nagahata. 2014 Acute Escherichia coli mastitis in dairy cattle: diagnostic param- 
eters associated with poor prognosis. J. Vet. Med. Sci. 76:14311436 .

Hernández, J., J. L. Benedito, A. Abuelo, and C. Castillo. 2014. Ruminal acidosis in feedlot: From aetiology to prevention. Sci. World J. 2014:702572.

Jeroch, H., W. Drochner, and O. Simon. 2008. Ernährung landwirtschaftlicher nutztiere. Ulmer, UTB.Stuttgart (Hohenheim), Germany.

Khafipour, E., S. Li, J. C. Plaizier, and D. O. Krause. 2009. Rumen microbiome composition determined using two nutritional models of subacute ruminal acidosis. Appl. Environ. Microbiol. 75:7115-7124.

Kleen, J. L., and C. Cannizzo. 2012. Incidence, prevalence and impact of SARA in dairy herds. Anim. Feed Sci. Technol. 172:4-8.

Kleen, J. L., G. A. Hooijer, J. Rehage, and J. P. Noordhuizen. 2003. Subacute ruminal acidosis (SARA): A review. J. Vet. Med. A Physiol. Pathol. Clin. Med. 50:406-414.

Klevenhusen, F., P. Pourazad, S. U. Wetzels, M. Qumar, M. A. KholParisini, and Q. Zebeli. 2014. Technical note: Evaluation of a real-time wireless $\mathrm{pH}$ measurement system relative to intraruminal differences of digesta in dairy cattle. J. Anim. Sci. 92:5635-5639.

Lüttgenau, J., O. Wellnitz, D. Kradolfer, E. Kalaitzakis, S. E. Ulbrich, R. M. Bruckmaier, and H. Bollwein. 2016. Intramammary lipopolysaccharide infusion alters gene expression but does not induce lysis of the bovine corpus luteum. J. Dairy Sci. 99:4018-4031.

Morris, M., and L. Li. 2012. Molecular mechanisms and pathological consequences of endotoxin tolerance and priming. Arch. Immunol. Ther. Exp. (Warsz.) 60:13-18.

Neubauer, V., E. Humer, I. Kroeger, T. Braid, M. Wagner, and Q. Zebeli. 2016. Differences between reticular $\mathrm{pH}$ and the $\mathrm{pH}$ profile of fluid and solid phase in the rumen of dairy cows fed varying concentrate levels. J. Anim. Physiol. Anim. Nutr. (Berl.) Submitted.

Nocek, J. E. 1997. Bovine acidosis: Implications on laminitis. J. Dairy Sci. 80:1005-1028.

Perkins, K. H., M. J. VandeHaar, J. L. Burton, J. S. Liesman, R. J. Erskine, and T. H. Elsasser. 2002. Clinical responses to intramammary endotoxin infusion in dairy cows subjected to feed restriction. J. Dairy Sci. 85:1724-1731.

Petzl, W., J. Günther, T. Pfister, C. Sauter-Louis, L. Goetze, S. von Aulock, A. Hafner-Marx, H. J. Schuberth, H. M. Seyfert, and H. Zerbe. 2012. Lipopolysaccharide pretreatment of the udder protects against experimental Escherichia coli mastitis. Innate Immun. 18:467-477.

Plaizier, J. C., D. O. Krause, G. N. Gozho, and B. W. McBride. 2008. Subacute ruminal acidosis in dairy cows: The physiological causes, incidence and consequences. Vet. J. 176:21-31.

Pourazad, P., R. Khiaosa-Ard, M. Qumar, S. U. Wetzels, F. Klevenhusen, B. U. Metzler-Zebeli, and Q. Zebeli. 2016. Transient feeding of a concentrate-rich diet increases the severity of subacute ruminal acidosis in dairy cattle. J. Anim. Sci. 94:726-738.

Pyorala, S. 2003. Indicators of inflammation in the diagnosis of mastitis. Vet. Res. 34:565-578

Qumar, M., R. Khiaosa-Ard, P. Pourazad, S. Wetzels, F. Klevenhusen, W. Kandler, J. Aschenbach, and Q. Zebeli. 2016. Evidence of in vivo absorption of lactate and modulation of short chain fatty acid absorption from the reticulorumen of non-lactating cattle fed high concentrate diets. PLoS One 11: e0164192.

Schwaiger, T., K. A. Beauchemin, and G. B. Penner. 2013. Duration of time that beef cattle are fed a high-grain diet affects the recovery from a bout of ruminal acidosis: Short-chain fatty acid and lactate absorption, saliva production, and blood metabolites. J. Anim. Sci. 91:5743-5753.

Sepúlveda-Varas, P., K. L. Proudfoot, D. M. Weary, and M. A. G. von Keyserlingk. 2016. Changes in behaviour of dairy cows with clinical mastitis. Appl. Anim. Behav. Sci. 175:8-13.
Shuster, D. E., R. J. Harmon, J. A. Jackson, and R. W. Hemken. 1991. Suppression of milk production during endotoxin-induced mastitis. J. Dairy Sci. 74:3763-3774.

Shuster, D. E., M. E. Kehrli, and M. G. Stevens. 1993. Cytokine production during endotoxin-induced mastitis in lactating dairy cows. Am. J. Vet. Res. 54:80-85.

Steele, M. A., J. Croom, M. Kahler, O. AlZahlal, S. E. Hook, K. Plaizier, and B. W. McBride. 2011. Bovine rumen epithelium undergoes rapid structural adaptations during grain-subacute ruminal acidosis. Am. J. Physiol. Regul. Integr. Comp. Physiol. 300:R1515-R1523.

Van Soest, P. J., J. B. Robertson, and B. A. Lewis. 1991. Methods for dietary fiber, neutral detergent fiber, and nonstarch polysaccharides in relation to animal nutrition. J. Dairy Sci. 74:3583-3597.

VDLUFA (Association of German Agricultural Analytic and Research Institutes). 2012. Die Chemische Untersuchung von Futtermitteln. 8. Erg. 2012. VDLUFA-Verlag, Darmstadt, Germany.

Vels, L., C. M. Røntved, M. Bjerring, and K. L. Ingvartsen. 2009. Cytokine and acute phase protein gene expression in repeated liver biopsies of dairy cows with a lipopolysaccharide-induced mastitis. J. Dairy Sci. 92:922-934.

Vernay, M. C. M. B., O. Wellnitz, L. Kreipe, H. A. Van Dorland, and R. M. Bruckmaier. 2012. Local and systemic response to intramammary lipopolysaccharide challenge during long-term manipulated plasma glucose and insulin concentration in dairy cows. J. Dairy Sci. 95:2540-2549.

Wellnitz, O., E. T. Arnold, and R. M. Bruckmaier. 2011. Lipopolysaccharide and lipoteichoic acid induce different immune responses in the bovine mammary gland. J. Dairy Sci. 94:5405-5412.

Wetzels, S. U., E. Mann, B. U. Metzler-Zebeli, P. Pourazad, M. Qumar, F. Klevenhusen, B. Pinior, M. Wagner, Q. Zebeli, and S. SchmitzEsser. 2016. Epimural indicator phylotypes of transiently-induced subacute ruminal acidosis in dairy cattle. Front. Microbiol. 7:274.

Zebeli, Q., and B. N. Ametaj. 2009. Relationship between rumen lipopolysaccharide and mediators of inflammatory response with milk fat production and efficiency in dairy cows. J. Dairy Sci. 92:3800-3809.

Zebeli, Q., J. Dijkstra, M. Tafaj, H. Steingass, B. N. Ametaj, and W. Drochner. 2008. Modeling the adequacy of dietary fiber in dairy cows based on the responses of ruminal $\mathrm{pH}$ and milk fat production to composition of the diet. J. Dairy Sci. 91:2046-2066.

Zebeli, Q., S. M. Dunn, and B. N. Ametaj. 2011. Perturbations of plasma metabolites correlated with the rise of rumen endotoxin in dairy cows fed diets rich in easily degradable carbohydrates. J. Dairy Sci. 94:2374-2382.

Zebeli, Q., K. Ghareeb, E. Humer, B. U. Metzler-Zebeli, and U. Besenfelder. 2015. Nutrition, rumen health and inflammation in the transition period and their role on overall health and fertility in dairy cows. Res. Vet. Sci. 103:126-136.

Zebeli, Q., and B. U. Metzler-Zebeli. 2012. Interplay between rumen digestive disorders and diet-induced inflammation in dairy cattle. Res. Vet. Sci. 93:1099-1108.

Zehner, N., J. J. Niederhauser, F. Nydegger, A. Grothmann, M. Keller, M. Hoch, A. Haeussermann, and M. Schick. 2012. Validation of a new health monitoring system (RumiWatch) for combined automatic measurement of rumination, feed intake, water intake and locomotion in dairy cows. Pages 1-6 in International Conference of Agricultural Engineering CIGR. 8-12 July, Publ. Ageng, Valencia, Spain.

Zimov, J. L., N. A. Botheras, W. P. Weiss, and J. S. Hogan. 2011. Associations among behavioral and acute physiologic responses to lipopolysaccharide-induced clinical mastitis in lactating dairy cows. Am. J. Vet. Res. 72:620-627. 